\title{
Prevalence and molecular epidemiology of extended spectrum $\beta$-lactamase producing Escherichia coli from hospital and community settings in Egypt
}

\author{
Mohamed Metwally Abdel-Moaty ${ }^{1 *}$, Walaa Saeed Mohamed ${ }^{1}$, Saeed Mohamed Abdel-All ${ }^{1}$, Hoda Hamed El-Hendawy ${ }^{2}$ \\ ${ }^{1}$ Microbiology Department, National Organization of Drug Control and Research, Giza, Egypt. ${ }^{2}$ Botany and Microbiology Department, Faculty of Science, \\ Helwan University, Helwan, Egypt.
}

\section{ARTICLE INFO \\ Article history: \\ Received on: 13/11/2015 \\ Revised on: 20/12/2015 \\ Accepted on: 04/01/2016 \\ Available online: $26 / 01 / 2016$}

Key words:

Extended spectrum $\beta$ -

lactamase, ESBL, E. coli,

PCR, CTX-M.

\begin{abstract}
The prevalence and molecular epidemiology of Escherichia coli that produce extended spectrum $\beta$-lactamase (ESBL) in Cairo, Egypt was investigated. Ninety E. coli isolates were collected along the period of September to November 2012 from hospital and community settings. Antibiotic susceptibility of the E. coli isolates was determined by disk diffusion method. All isolates were screened phenotypically for ESBL production by combination disk method. The presence of ${ }^{\text {bla }} \mathrm{CTX}-\mathrm{M}-\mathrm{I}$, ${ }^{\text {bla }} \mathrm{CTX}-\mathrm{M}-\mathrm{IV}$, ${ }^{\text {bla TEM and }}{ }^{\text {bla }} \mathrm{SHV}$ genes in ESBLproducing E. coli was examined by PCR and sequencing experiments. The results showed high prevalence of ESBL-producing E. coli, $52 \%$ of the collected isolates were ESBL producers. The ESBL-producing isolates significantly $(P<0.05)$ had increased resistance compared with non-ESBL producers to cefuroxime, cefotaxime, ceftazidime, cefepime, ciprofloxacin, and co-trimoxazole. Imipenem was the most effective drug against ESBL producing isolates. All ESBL producing E. coli isolates were multi drug resistant (MDR) to eight antibiotics or more. Detection of ESBL genes in selected MDR-ESBL producing E. coli revealed that ${ }^{\text {bla }} \mathrm{CTX}-\mathrm{M}-\mathrm{I}$ was the most prevalent ESBL type. It is clear that the prevalence of ESBL producing E. coli in Cairo, Egypt is alarming high. This study is useful for clinician in order to improve the empiric treatment.
\end{abstract}

\section{INTRODUCTION}

In the early 1980s, third-generation cephalosporins were introduced to the clinical practice as $\beta$-lactam antibiotics able to overcome resistance caused by the common $\beta$-lactamases produced by Escherichia coli (Livermore, 2012). However, within few years; $E$. coli produced mutated versions of these $\beta$ lactamases called extended spectrum $\beta$-lactamases (ESBLs) which enable them to neutralize the activity of expandedspectrum cephalosporins, and monobactams (Livermore, 2012). ESBLs are enzymes capable of conferring bacteria resistance to penicillins, $1^{\text {st }}, 2^{\text {nd }}, 3^{\text {rd }}, 4^{\text {th }}$ generation cephalosporins, and monobactams by hydrolysis of these antibiotics. ESBLs do not hydrolyze cephamycins (e.g., cefoxitin or cefotetan) or carbapenems (e.g., imipenem and meropenem), and they are inhibited by $\beta$-lactamase inhibitors such as clavulanic acid (Paterson and Bonomo, 2005). The majority of ESBLs belongs to class A Ambler classification which includes the ${ }^{\text {bla }} \mathrm{SHV}$, ${ }^{\text {bla }} \mathrm{TEM}$,

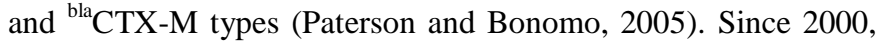

\footnotetext{
* Corresponding Author

Email:metwally@ymail.com
}

E. coli producing ${ }^{\text {bla } C T X-M}$ have emerged worldwide as an important cause of community-onset UTIs (Lahlaoui et al., 2014). ESBLs are mostly encoded by large plasmids (up to $100 \mathrm{~kb}$ and even more) that are transferable from strain to strain and between bacterial species (AitMhand et al., 2002). Genes encoding ESBLs are frequently found on the same plasmid as genes encoding resistance for other classes of antibiotics such as aminoglycosides, tetracyclines, and sulfonamides. Taking into the account, many of E. coli strains possess chromosomal changes that confer resistance to fluoroquinolones (Livermore, 2012). As a result, ESBL producing $E$. coli is frequently multidrug resistant (MDR), posing particular difficulties in the treatment of infections, especially in critically ill patients. ESBL-producing E. coli have recently reported in Egypt (Abdul Rahman and El-Sherif, 2011). A more comprehensive survey of ESBLs from Egypt is urgently needed not only for the hospital setting but also for the community. This study was carried out to determine the prevalence of ESBLproducing E. coli in hospital and community settings in Cairo, Egypt and to assess antibiotic susceptibility patterns of these isolates in order to define appropriate antimicrobial therapy. We are also aimed to reveal basic aspects of the molecular epidemiology of these isolates in Cairo, Egypt. 


\section{MATERIALS AND METHODS}

\section{Bacterial isolates}

Bacterial isolates were collected along the period of September to November 2012 from three hospitals (University of Ain Shams Hospital, El-Salam International Hospital, National Cancer Institute) and two community clinical labs (Cairo Lab Helwan branch, Shaker Lab - Misr El-Gedida branch). The isolates were non-consecutive (Only a single positive culture per patient). Isolates were streaked on Tryptic soy agar medium to ensure purity and viability.

Isolates that were gram-negative, lactose-fermenting, non-swarming, indole positive, oxidase negative, producing acid slant/acid butt reaction with or without gas on triple sugar iron medium test, citrate negative and urease negative identified as $E$. coli (Engelkirk and Duben-Engelkirk, 2007). Isolates identified as E. coli, were stored on glycerol Tryptic soy broth at $-20^{\circ} \mathrm{C}$ freezer. When a fresh seed-stock vial is required, it was removed and used to inoculate a series of working cultures. Quality control strains; E. coli ATCC 25922 and Klebsiella pneumoniae ATCC 700603 were kindly provided by the U.S. naval medical research unit no. 3 (NAMRU-3) in Egypt.

\section{Antibiotic susceptibility testing and phenotypic ESBL detection}

Antibiotic susceptibility of the E. coli isolates was determined by Kirby-Bauer disk diffusion method according to CLSI recommendations (Bauer et al., 1966; CLSI 2009). Antibiotics to be tested; were selected referring to CLSI document M100-S21 (CLSI, 2011). Antibiotics discs were obtained from Oxoid (UK) and they included cephalothin $(30 \mu \mathrm{g})$, cefuroxime (30 $\mu \mathrm{g})$, co-amoxiclav $(20 / 10 \mu \mathrm{g})$, cefotaxime $(30 \mu \mathrm{g})$, ceftazidime $(30 \mu \mathrm{g})$, ceftriaxone $(30 \mu \mathrm{g})$, cefepime $(30 \mu \mathrm{g})$, imipenem $(10 \mu \mathrm{g})$, gentamicin $(10 \mu \mathrm{g})$, ciprofloxacin $(5 \mu \mathrm{g})$, and co-trimoxazole $(1.25 / 23.75 \mu \mathrm{g})$.

The diameters of the inhibition zones were interpreted by referring to CLSI document M100-S21 (CLSI, 2011), and the examined isolates were reported as susceptible, intermediate, or resistant to the agents under test. Control strain used to validate susceptibility tests was E. coli ATCC 25922. Quality control strain was tested daily to ensure the test system is working and gives results within specified limits.

All tested E. coli isolates were screened for ESBL production. Combination disk method as recommended by (CLSI, 2011) was used. ESBL Kits were obtained from Himedia (India) and they included cefotaxime $(30 \mu \mathrm{g})$, cefotaxime/clavulinic acid $(30 / 10 \mu \mathrm{g})$, ceftazidime $(30 \mu \mathrm{g})$, and ceftazidime/clavulinic acid (30/10 $\mu \mathrm{g})$.

ESBL testing requires use of both cefotaxime and ceftazidime, alone and in combination with clavulinic acid, $\geq 5$ $\mathrm{mm}$ increase in a zone diameter for either antibiotic (ceftazidime or cefotaxime) tested in combination with clavulinic acid versus its zone when tested alone was determined to be ESBL producer. E. coli ATCC 25922 (negative control) and Klebsiella pneumoniae
ATCC 700603 (positive control) were used as quality control strains.

\section{Statistical analysis}

Fisher exact test (Agresti, 1992) was used as a statistical tool to determine the significance of difference between the resistance level to various antibiotics in ESBL and non ESBL producing isolates, $P<0.05$ was considered significant.

\section{Detection of ESBL genes PCR amplification}

Boiling lyses method was used for extraction of DNA from isolates under test (Moore et al., 2004). Klebsiella pneumoniae ATCC 700603 was used as positive ESBL producer ( ${ }^{\text {bla }}$ SHV-type). Primers (Biosearch Technologies, USA) were purchased in lyophilized form. DreamTaq Green PCR Master Mix (2X) (Thermo Scientific, USA) containing (DreamTaq DNA polymerase, 2X DreamTaq green buffer, dATP, dCTP, dGTP, dTTP, $0.4 \mathrm{mM}$ each, and $4 \mathrm{mM} \mathrm{MgCl}_{2}$ ) was used. PCR amplification was used to identify the presence of bla ${ }^{\mathrm{CTX}-\mathrm{M} \text { genes }}$

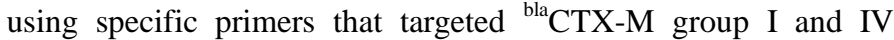
(Pitout et al., 2004). The presence of genes encoding ${ }^{\text {bla }} \mathrm{TEM}$ and

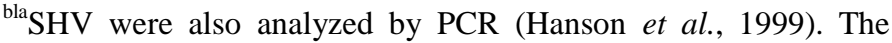
primers sequence, sizes of the expected amplification product and nucleotide positions are listed in Table 1.

Amplifications of ESBL genes were carried out on a DNA Thermal Cycler instrument (PTC-100; MJ Resrach Inc, USA). The composition of the reaction mixture was as follows: $12.5 \mu \mathrm{l}$ of DreamTaq Green PCR Master Mix (2X), $3 \mu \mathrm{l}$ of bacterial lysate, $1 \mu \mathrm{l}$ of each primer $(10 \mathrm{pM} / \mu \mathrm{l})$, and nuclease-free water was added to complete a final PCR reaction volume to $25 \mu \mathrm{l}$; the mixture was mixed gently before running the PCR program. The PCR program consisted of an initial denaturation step at $96^{\circ} \mathrm{C}$ for 4 minutes, followed by 24 cycles of; DNA denaturation at $96^{\circ} \mathrm{C}$ for 30 seconds, primer annealing at $55^{\circ} \mathrm{C}$ for 30 seconds, and primer extension at $72^{\circ} \mathrm{C}$ for $2 \mathrm{~min}$, and final elongation step at $72^{\circ} \mathrm{C}$ for 10 minutes (Pitout et al., 1998). Aliquots of $10 \mu \mathrm{l}$ of PCR products were analyzed by gel electrophoresis with $1.6 \%$ agarose gels in $1 \times$ TAE buffer for 30 minutes at $90 \mathrm{~V}$. Gels were stained with $2 \mu \mathrm{l}$ ethidium bromide ( $10 \mathrm{mg} / \mathrm{L})$, visualized and compared to 100 bp DNA ladder (fisher bioreagents, Canada) by UV transilluminator.

\section{Sequencing of ESBL genes}

Randomly selected products from the CTX-M group I and CTX-M group IV PCRs were sequenced on an Applied Biosystems 3100 DNA Analyser to identify the specific ESBL type. The primers used for sequencing were the same as those used for PCR. The PCR products were purified with high pure PCR product purification kits (Roche Molecular Biochemicals, Espoo, Finland). ABI BigDyeTM terminator cycle sequencing kit version 3.1 (Applied Biosystems, Espoo, Finland) was used. The DNA sequences were analysed and translated into amino acid sequences with DNA sequencing analysis software, version 5.3.1 (Applied 
Biosystems, Espoo, Finland). Amino acid sequences were compared to the known CTX-M variants by BLAST at website search (http://www.ncbi.nlm.nih.gov/blast).

\section{RESULTS AND DISCUSSION}

ESBLs are now commonly found in E. coli isolates from patients in nursing homes and long term- care facilities, and even in patients with community-acquired infections (Lahlaoui et al., 2014). In this study; during the 3 months study period; a total of 90 E. coli isolates were collected from three hospitals included University of Ain Shams Hospital (32 isolates), El Salam International Hospital (32 isolates), National Cancer Institute (6 isolates), and two clinical community labs included Cairo Lab Helwan branch (10 isolates), Shaker Lab - Misr El Gedida branch (10 isolates). The majority of isolates were from urine samples (67 isolates). There were 7 isolates from stool samples, 5 from sputum samples, 4 from pus samples, 2 from groin samples, 2 from drainage samples, and 3 isolates from miscellaneous sites.

High prevalence level of ESBL producing E. coli was recorded in the present study, as of the $90 \mathrm{E}$. coli isolates collected; 47 (52\%) were ESBL producers (Table 2). Many studies from Egypt also recorded high percentage of ESBL production among E. coli isolates. In a study carried out at Cairo University Hospitals, 400 bacterial isolates from 632 stool samples were found to be ESBL producers. Out of these 400 isolates, 285 (71.25\%) were identified as E. coli (Abdul Rahman and El-Sherif, 2011). In another study from Egypt, which included only blood stream infections in patients admitted to intensive care units (ICUs), the proportion of ESBL-producing E. coli was 39\% (Saied et al., 2011). In contrast to our results, low prevalence level of ESBL-producing E. coli was reported in many African countries such as Morocco (1.3\%) (Barguigua, et al., 2011), Nigeria (12.8\%) (Aibinu et al., 2012), and South Africa (7.6\%) (Brink et al., 2012). Prevalence of ESBL producing E. coli isolates in the United States and Europe was lower than that reported in Egypt. Bhusal, et al. (2011) reported that out of $443 \mathrm{E}$. coli isolated from cancer patients at a cancer center in USA, only $41(9.2 \%)$ isolates were ESBL producers.

Also, Hawser et al. (2011) examined 3160 isolates of $E$. coli collected from 44 hospitals in different European countries (i.e. France, Germany, Greece, Romania, Spain, Turkey, Estonia, Italy, Latvia, Lithuania, Portugal, and UK), and found that only $11 \%$ of isolates were ESBL producers. Variable percentage of ESBL-producing E. coli was reported in Asia by different workers, for example, a study from India reported that $30 \%$ of $E$. coli isolates obtained from different clinical samples were found to be ESBL producers (Agrawal et al., 2008). On the other hand; in Taiwan; Hsieh et al. (2010) conducted a study on hospitalized patients with $E$. coli bacteremia, and found that the frequency of ESBL producers was $4.7 \%$. As it was expected, all ESBL producing $E$. coli isolates in this study were resistant to all cephalosporins tested (Table 2).

It was also noted that ESBL producing $E$. coli had significantly $(\mathrm{P}<0.05)$ diminished susceptibility compared with non ESBL producers for all cephalosporin tested (cefuroxime, cefotaxime, ceftazidime, ceftriaxone, cefepime), except cephalothin. This finding is in accordance with other reports (Koksal et al., 2009; Gorgec et al., 2015). Some studies mentioned that co-amoxiclav may have considerable antimicrobial activity against ESBL producing $E$. coli isolated in the community, and it may constitute an effective therapeutic option for communityacquired urinary tract infections caused by ESBL-producing $E$. coli (Falgas et al., 2008).

Table 1: Primers used for amplification of DNA of ESBL genes.

\begin{tabular}{lllcc}
\hline Targets & Primers & Sequence 5' to 3' & Product size & Nucleotide positions \\
\hline \multirow{2}{*}{ CTX-M group I } & (forward) & GAC GAT GTC ACT GGC TGA GC & $416-435$ \\
& (reverse) & AGC CG C CGA CGC TAA TAC A & $914-896$ \\
\hline \multirow{2}{*}{ CTX-M group IV } & (forward) & GCT GGA GAA AAG CAG CGG AG & 474 & $1857-1876$ \\
& (reverse) & GTA AGC TGA CGC AAC GTC TG & $2330-2311$ \\
\hline \multirow{2}{*}{ TEM } & (forward) & AGA TCA GTT GGG TGC ACG AG & 750 & $313-332$ \\
& (reverse) & TGC TTA ATC AGT GAG GCA CC & $1061-1042$ \\
\hline \multirow{2}{*}{ SHV } & (forward) & GGGAACGGAACTGAATGAG & 149 & $606-625$ \\
& (reverse) & ATCGTCCACCATCCACTGCA & $757-738$ \\
\hline
\end{tabular}

Group I includes CTX-M-1, -3, -10 to -12, -15 (UOE-1), -22, -23, -28, -29, and -30

Group IV includes CTX-M-9, $-13,-14,-16$ to -19 and -21 , and -27 and Toho-2.

Table 2: The antimicrobial resistance percentages of ESBL-producing and non ESBL-producing E. coli isolates.

\begin{tabular}{|c|c|c|c|c|c|c|c|}
\hline \multirow{3}{*}{ Antibiotics } & \multicolumn{4}{|c|}{$E$. coli isolates $(n=90)$} & \multirow{3}{*}{ P-value } & \multirow{2}{*}{\multicolumn{2}{|c|}{ Resistant isolates }} \\
\hline & \multicolumn{2}{|c|}{ ESBL-producing $(n=47: 52 \%)$} & \multicolumn{2}{|c|}{ non ESBL-producing $(n=43: 48 \%)$} & & & \\
\hline & $\mathbf{n}$ & $\%$ & $\mathbf{n}$ & $\%$ & & $\mathbf{n}$ & $\%$ \\
\hline Cephalothin & 47 & 100 & 41 & 95 & 0.225 & 88 & 98 \\
\hline Cefuroxime & 47 & 100 & 30 & 70 & $<0.05$ & 77 & 86 \\
\hline Co-amoxiclav & 34 & 72 & 33 & 77 & 0.809 & 67 & 74 \\
\hline Cefotaxime & 47 & 100 & 17 & 39 & $<0.05$ & 64 & 71 \\
\hline Ceftazidime & 47 & 100 & 11 & 26 & $<0.05$ & 58 & 64 \\
\hline Ceftriaxone & 47 & 100 & 8 & 19 & $<0.05$ & 55 & 61 \\
\hline Cefepime & 47 & 100 & 11 & 26 & $<0.05$ & 58 & 64 \\
\hline Imipenem & 0 & -- & 0 & -- & N/D & 0 & -- \\
\hline Gentamicin & 20 & 43 & 15 & 35 & 0.519 & 35 & 39 \\
\hline Ciprofloxacin & 40 & 85 & 18 & 42 & $<0.05$ & 58 & 64 \\
\hline Co-trimoxazole & 42 & 89 & 29 & 67 & $<0.05$ & 71 & 79 \\
\hline
\end{tabular}

The difference in resistance level between ESBL and non ESBL isolates was significant at $p<0.05$. 
In our study; ESBL E. coli showed high resistance percentage against co-amoxiclav $(72 \%)$ which might suggest that co-amoxiclav is not the suitable drug for treatment of infections caused by ESBL producing $E$. coli in our country.

Co-resistance to non- $\beta$-lactam antibiotics is common among ESBL producers, especially for fluoroquinolones, cotrimoxazole and/or aminoglycosides. In this study, the obtained results revealed that; resistance level to ciprofloxacin and cotrimoxazole was highly significant in ESBL producing E. coli in comparison with non ESBL producing isolates, however; there was no significant difference in the resistance level to gentamicin between ESBL producing and non ESBL producing E. coli (Table 2).

Other studies reported high degree of resistance to fluoroquinolones and co-trimoxazole and less resistance degree to gentamicin among ESBL producing E. coli when compared to non-ESBL producing E. coli (Chander and Shrestha, 2013, Somily, et al., 2014). In contrast to our results; some studies reported significant difference of resistance level to gentamicin between ESBL producing and non ESBL producing E. coli (Cagan Aktas et al., 2014).

All ESBL producing E. coli isolates in this study were susceptible to imipenem (Table 2), indicating that it could be the proper drug for treating serious infections caused by ESBL producing E. coli. Many studies reported high susceptibility rate to imipenem (100\%) among ESBL producing E. coli (Hawser et al., 2011, El-Bouamri et al., 2014). In this study, E. coli isolates expressed multi drug resistance (MDR) phenotype at high level. Eighty six $(95 \%)$ isolates were found to be resistant to 3 or more antibiotic classes (Table 3).

MDR level was higher among ESBL producers than in non-ESBL producers; all ESBL producing E. coli were resistant to 8 antibiotics or more. Other workers also found high proportions of multidrug resistance among ESBL producers (Serefhanoglu et al., 2009; Chander and Shrestha, 2013). High resistance level to all antibiotics used in this study with the exception of imipenem and high prevalence of MDR-ESBL producing E. coli detected in our study as well as in the previous reports from Egypt compared to other countries, may be attributed to the uncontrolled consumption of large amount of antibiotics by patients in Egypt.

A patient's previous exposure to an antibiotic, especially to extended spectrum cephalosporins, and fluoroquinolones has been widely reported as a risk factor for infection with ESBLproducing bacteria (Hsieh et al., 2010; Goulenok et al., 2013). Twelve ESBL-producer E. coli isolates; which showed resistance to 10 antibiotics in the test panel (Table 3); were further subjected to PCR assay for the detection of ESBL genes and the results

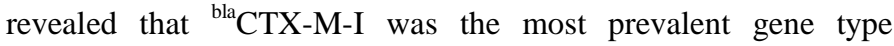
(Table 4).

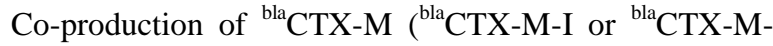
IV) with ${ }^{\text {bla }}$ TEM enzymes was observed in 8 isolates. Sequencing

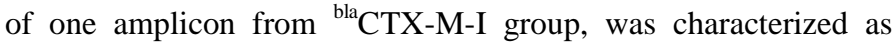
${ }^{\text {bla }}$ CTX-M-15 enzyme, the sequence obtained was submitted to GenBank under KP325147.1 accession number. Sequencing of one amplicon from ${ }^{\text {bla }}$ CTX-M-IV group was characterized as

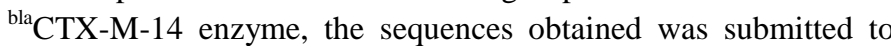
GenBank under NG_041766.1 accession number.

Table 3: Antibiotic resistance pattern of the multi drug resistant (MDR) E. coli isolates.

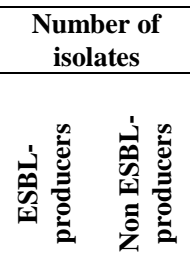

\begin{tabular}{|c|c|c|}
\hline \multicolumn{3}{|l|}{ Resistance to (3) antibiotics } \\
\hline $\mathrm{CL}, \mathrm{AMC}, \mathrm{CN}$ & 0 & 2 \\
\hline CL, CXM, AMC & 0 & 2 \\
\hline Other patterns & 0 & 5 \\
\hline \multicolumn{3}{|l|}{ Resistance to (4) antibiotics } \\
\hline CL, CXM, AMC, SXT & 0 & 3 \\
\hline $\mathrm{CL}, \mathrm{AMC}, \mathrm{CN}, \mathrm{SXT}$ & 0 & 2 \\
\hline CL, AMC, CIP, SXT & 0 & 2 \\
\hline Other patterns & 0 & 2 \\
\hline \multicolumn{3}{|l|}{ Resistance to (5) antibiotics } \\
\hline CL, CXM, AMC, CN, SXT & 0 & 2 \\
\hline Other patterns & 0 & 2 \\
\hline \multicolumn{3}{|l|}{ Resistance to (6) antibiotics } \\
\hline CL, CXM, AMC, CTX, CIP, SXT & 0 & 2 \\
\hline Other patterns & 0 & 3 \\
\hline \multicolumn{3}{|l|}{ Resistance to (7) antibiotics } \\
\hline CL, CXM, AMC, CTX, CRO, FEP, SXT & 0 & 1 \\
\hline CL, CXM, CTX, CAZ, CRO, FEP, SXT & 0 & 1 \\
\hline Other patterns & 0 & 4 \\
\hline \multicolumn{3}{|l|}{ Resistance to (8) antibiotics } \\
\hline CL, CXM, CTX, CAZ, CRO, FEP, CIP, SXT & 7 & 1 \\
\hline CL, CXM, CTX, CAZ, CRO, FEP, CN, CIP & 3 & 0 \\
\hline CL, CXM, CTX, CAZ, CRO, FEP, CN, SXT & 3 & 0 \\
\hline CL, CXM, AMC, CTX, CAZ, CRO, FEP, CIP & 2 & 0 \\
\hline CL, CXM, AMC, CTX, CAZ, CRO, FEP, SXT & 2 & 0 \\
\hline Other patterns & 0 & 1 \\
\hline \multicolumn{3}{|l|}{ Resistance to (9) antibiotics } \\
\hline CL, CXM, AMC, CTX, CAZ, CRO, FEP, CIP, SXT & 16 & 3 \\
\hline CL, CXM, AMC, CTX, CAZ, CRO, FEP, CN, SXT & 2 & 0 \\
\hline \multicolumn{3}{|l|}{ Resistance to (10) antibiotics } \\
\hline $\begin{array}{l}\text { CL, CXM, AMC, CTX, CAZ, CRO, FEP, CN, CIP, } \\
\text { SXT }\end{array}$ & 12 & 1 \\
\hline
\end{tabular}

Table 4: Occurrence of different ESBL genes among the selected 12 MDRESBL E. coli isolates.

\begin{tabular}{lc}
\hline ESBL genes & Number of $\boldsymbol{E}$. coli isolates \\
\hline${ }^{\text {blacTX-M-I group }}$ & 11 \\
bla CTX-M-I group only & 4 \\
bla CTX-M-I group plus ${ }^{\text {bla }}$ TEM & 7 \\
${ }^{\text {bla }}$ CTX-M-IV group & 1 \\
${ }_{\text {bla CTX-M-IV group only }}^{\text {bla }}$ & 0 \\
bla CTX-M-IV group plus ${ }^{\text {bla }}$ & 1 \\
${ }^{\text {bla } T E M \text { only }}$ & 0 \\
${ }^{\text {bla SHV }}$ & 0 \\
\hline
\end{tabular}

Many studies also reported that ${ }^{\text {bla } C T X-M-I ~ w a s ~ t h e ~ m o s t ~}$ prevalent type among ESBL producing E. coli in Egypt. For example, Fam et al. (2011) collected 47 E. coli isolates from all specimens' types at Theodor Bilharz research institute in Egypt, and examined them for presence of ESBL genes. The obtained 
results showed that the all 47 isolatess produced ${ }^{\text {bla }} \mathrm{CTX}-\mathrm{M}-15$ which belongs to ${ }^{\text {bla }} \mathrm{CTX}-\mathrm{M}-\mathrm{I}$ group. In another study, also carried out at Theodor Bilharz research institute on $44 \mathrm{E}$. coli isolates

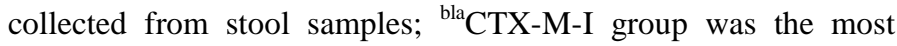
prevalent enzyme; detected in 29 isolates, whereas ${ }^{\text {bla }} \mathrm{CTX}-\mathrm{M}-\mathrm{IV}$ group genes were detected in 14 isolates (Fam et al., 2014). Coproduction of ${ }^{\text {bla }} \mathrm{CTX}-\mathrm{M}$ and ${ }^{\text {bla }} \mathrm{TEM}$ in ESBL producing E. coli was previously reported in other studies from Egypt (Al-Agamy et al., 2006) and Turkey (Gorgec et al., 2015).Worldwide; several studies reported that ${ }^{\text {bla }} \mathrm{CTX}-\mathrm{M}$ was the most prevalent ESBL type among ESBL producing E. coli (Hoban et al., 2014; Wang et al., 2014, Gorgec et al., 2015).

\section{CONCLUSION}

Our data pointed out that the prevalence of ESBLproducing E. coli is high in Cairo, Egypt. Carbapenems should be regarded as the drugs of choice for serious infections with ESBL producing $E$. coli. If the causative agent has been found as susceptible to other antibiotics such as aminoglycosides, they can be used in the treatment of non-life-threatening infections caused by ESBL producing $E$. coli to reduce carbapenem utilization. The ${ }^{\text {bla } C T X-M-I ~ g r o u p ~ w a s ~ t h e ~ m o s t ~ p r e v a l e n t ~ E S B L ~ t y p e, ~ e s p e c i a l l y ~ i n ~}$ combination with blaTEM enzymes. Continued surveillance, appropriate use of antibiotics, and implementation of strict infection control measures are recommended to decrease ESBL frequency.

\section{REFERENCES}

Abdul Rahman EM and El-Sherif RH. High rates of intestinal colonization with extended-spectrum lactamase-producing Enterobacteriaceae among healthy individuals. J Investig Med, 2011; 59:1284-1286.

Agrawal P, Ghosh AN, Kumar S, Basu B, Kapila K. Prevalence of extended-spectrum beta-lactamases among Escherichia coli and Klebsiella pneumoniae isolates in a tertiary care hospital. Indian J Pathol Microbiol, 2008; 51:139-142.

Agresti A. A survey of exact inference for contingency tables. Stat Sci, 1992; 7:131-153.

Aibinu I, Odugbemi T, Koenig W, Ghebremedhin B. Sequence type ST131 and ST10 complex (ST617) predominant among CTX-M-15producing Escherichia coli isolates from Nigeria. Clin Microbiol Infect, 2012; 18:E49-51.

AitMhand R, Soukri A, Moustaoui N, Amarouch H, ElMdaghri N, Sirot D, Benbachir M. Plasmid-mediated TEM-3 extended-spectrum beta-lactamase production in Salmonella typhimurium in Casablanca. J Antimicrob Chemother, 2002; 49:169-172.

Al-Agamy MH, El-Din Ashour MS, Wiegand I. First description of CTX-M beta-lactamase-producing clinical Escherichia coli isolates from Egypt. Int J Antimicrob Agents, 2006; 27:545-548.

Barguigua A, El Otmani F, Talmi M, Bourjilat F, Haouzane F, Zerouali K, Timinouni M. Characterization of extended-spectrum betalactamase-producing Escherichia coli and Klebsiella pneumoniae isolates from the community in Morocco. J Med Microbiol, 2011; 60:1344-1352.

Bauer AW, Kirby WM, Sherris JC, Turck M. Antibiotic susceptibility testing by a standardized single disk method. Am J Clin Pathol, 1966; 45:493-496.

Bhusal Y, Mihu CN, Tarrand JJ, Rolston KV. Incidence of fluoroquinolone-resistant and extended-spectrum beta-lactamaseproducing Escherichia coli at a comprehensive cancer center in the United States. Chemotherapy, 2011; 57:335-338.
Brink AJ, Botha RF, Poswa X, Senekal M, Badal RE, Grolman DC, Richards GA, Feldman C, Boffard KD, Veller M, et al. Antimicrobial susceptibility of gram-negative pathogens isolated from patients with complicated intra-abdominal infections in South African hospitals (SMART Study 2004-2009): impact of the new carbapenem breakpoints. Surg Infect (Larchmt), 2012; 13:43-49.

Cagan Aktas S, Gencer S, Batirel A, Haciseyitoglu D, Ozer S. Fosfomycin susceptibility of urinary Escherichia coli isolates producing extended-spectrum beta-lactamase according to CLSI and EUCAST recommendations. Mikrobiyol Bul, 2014; 48:545-555.

Chander A and Shrestha CD. Prevalence of extended spectrum beta lactamase producing Escherichia coli and Klebsiella pneumoniae urinary isolates in a tertiary care hospital in Kathmandu, Nepal. BMC Res Notes, 2013; 6:487-492.

CLSI. 2009. Performance standards for antimicrobial disk susceptibility tests; Approved standard - tenth edition. CLSI document M2-A10. Clinical and Laboratory Standards Institute, Pennsylvania, USA.

CLSI. 2011. Performance standards for antimicrobial susceptibility testing; Twenty-first informational supplement. CLSI document M100-S21. Clinical and Laboratory Standards Institute, Pennsylvania, USA.

El Bouamri MC, Arsalane L, Kamouni Y, Yahyaoui H, Bennouar N, Berraha M, Zouhair S. Current antibiotic resistance profile of uropathogenic Escherichia coli strains and therapeutic consequences. Prog Urol, 2014; 24:1058-1062.

Engelkirk PG and Duben-Engelkirk J. 2007. Gram Negative Bacilli: The Family Enterobacteriaceae. In: Engelkirk Paul G and Janet Duben-Engelkirk, ed. Laboratory Diagnosis of Infectious Diseases: Essentials of Diagnostic Microbiology. Philadelphia: Lippincott Williams \& Wilkins 292-318.

Falagas ME, Polemis M, Alexiou VG, Marini-Mastrogiannaki A, Kremastinou J, Vatopoulos AC. Antimicrobial resistance of Esherichia coli urinary isolates from primary care patients in Greece. Med Sci Monit, 2008; 14:CR75-79.

Fam N, Leflon-Guibout V, Fouad S, Aboul-Fadl L, Marcon E, Desouky D, El-Defrawy I, Abou-Aitta A, Klena J, Nicolas-Chanoine MH. CTX-M-15-producing Escherichia coli clinical isolates in Cairo (Egypt), including isolates of clonal complex ST10 and clones ST131, ST73, and ST405 in both community and hospital settings. Microb Drug Resist, 2011; 17:67-73.

Fam NS, Defasque S, Bert F, Leflon-Guibout V, El-Ray A, ElGhannam M, Attia ME, Omar M, Desouki DG, Valla D, et al. Faecal carriage of extended-spectrum beta-lactamase (ESBL)-producing enterobacteria in liver disease patients from two hospitals in Egypt and France: a comparative epidemiological study. Epidemiol Infect, 2014; 143:1247-1255.

Gorgec S, Kuzucu C, Otlu B, Yetkin F, Ersoy Y. Investigation of beta-lactamase genes and clonal relationship among the extendedspectrum beta-lactamase producing nosocomial Escherichia coli isolates. Mikrobiyol Bul, 2015; 49: 15-25.

Goulenok T, Ferroni A, Bille E, Lecuyer H, Join-Lambert O, Descamps P, Nassif X, Zahar JR. Risk factors for developing ESBL $E$. coli: can clinicians predict infection in patients with prior colonization? J Hosp Infect, 2013; 84: 294-299.

Hanson ND, Thomson KS, Moland ES, Sanders CC, Berthold G, Penn RG. Molecular characterization of a multiply resistant Klebsiella pneumoniae encoding ESBLs and a plasmid-mediated AmpC. J Antimicrob Chemother, 1999; 44:377-380.

Hawser SP, Bouchillon SK, Lascols C, Hackel M, Hoban DJ, Badal RE, Canton R. Susceptibility of European Escherichia coli clinical isolates from intra-abdominal infections, extended-spectrum betalactamase occurrence, resistance distribution, and molecular characterization of ertapenem-resistant isolates (SMART 2008-2009). Clin Microbiol Infect, 2011; 18: 253-259.

Hoban DJ, Badal R, Bouchillon S, Hackel M, Kazmierczak K, Lascols C, Hawser S. In vitro susceptibility and distribution of betalactamases in Enterobacteriaceae causing intra-abdominal infections in North America 2010-2011. Diagn Microbiol Infect Dis, 2014; 79:367-372. 
Hsieh CJ, Shen YH, Hwang KP. Clinical implications, risk factors and mortality following community-onset bacteremia caused by extended-spectrum beta-lactamase (ESBL) and non-ESBL producing Escherichia coli. J Microbiol Immunol Infect, 2010; 43:240-248.

Koksal F, Ak K, Kucukbasmaci O, Samasti M. Prevalence and antimicrobial resistance patterns of extended-spectrum beta-lactamaseproducing Escherichia coli and Klebsiella pneumoniae isolated from blood cultures in an Istanbul University Hospital. Chemotherapy, 2009; 55:293297.

Lahlaoui H, Ben Haj Khalifa A, Ben Moussa M. Epidemiology of Enterobacteriaceae producing CTX-M type extended spectrum betalactamase (ESBL). Med Mal Infect, 2014; 44:400-404.

Livermore DM. Current Epidemiology and Growing Resistance of Gram-Negative Pathogens. Korean J Intern Med, 2012; 27:128-142.

Moore E, Arnscheidt A, Kruger A, Strompl C, Mau M. 2004. Section 1 update: Simplified protocols for the preparation of genomic DNA from bacterial cultures. In: Kowalchuk George A, ed. Molecular Microbial Ecology Manual. Dordrecht: Kluwer Academic 3-18.

Paterson DL and Bonomo RA. Extended-spectrum betalactamases: a clinical update. Clin Microbiol Rev, 2005; 18:657-686.

Pitout JD, Hossain A, Hanson ND. Phenotypic and molecular detection of CTX-M-beta-lactamases produced by Escherichia coli and Klebsiella spp. J Clin Microbiol, 2004; 42:5715-5721.

Pitout JD, Thomson KS, Hanson ND, Ehrhardt AF, Moland ES, Sanders CC. beta-Lactamases responsible for resistance to expanded-spectrum cephalosporins in Klebsiella pneumoniae, Escherichia coli, and Proteus mirabilis isolates recovered in South Africa. Antimicrob Agents Chemother, 1998; 42:1350-1354.
Saied T, Elkholy A, Hafez SF, Basim H, Wasfy MO, ElShoubary W, Samir A, Pimentel G, Talaat M. Antimicrobial resistance in pathogens causing nosocomial bloodstream infections in university hospitals in Egypt. Am J Infect Control, 2011; 39:e61-e65.

Serefhanoglu K, Turan H, Timurkaynak FE, Arslan $H$. Bloodstream infections caused by ESBL-producing $E$. coli and $K$. pneumoniae: risk factors for multidrug-resistance. Braz J Infect Dis, 2009; 13:403-407.

Somily AM, Habib HA, Absar MM, Arshad MZ, Manneh K, Al Subaie SS, Al Hedaithy MA, Sayyed SB, Shakoor Z, Murray TS. ESBLproducing Escherichia coli and Klebsiella pneumoniae at a tertiary care hospital in Saudi Arabia. J Infect Dev Ctries, 2014; 8:1129-1136.

Wang Y, Zhao S, Han L, Guo X, Chen M, Ni Y, Zhang Y, Cui Z, He P. Drug resistance and virulence of uropathogenic Escherichia coli from Shanghai, China. J Antibiot (Tokyo), 2014; 67:799-805.

\section{How to cite this article:}

Abdel-Moaty MM, Mohamed WS, Abdel-All SM, El-Hendawy $\mathrm{HH}$. Prevalence and molecular epidemiology of extended spectrum $\beta$-lactamase producing Escherichia coli from hospital and community settings in Egypt. J App Pharm Sci, 2016; 6 (01): 042047. 